\title{
ENERGY PRODUCTION FROM WASTES BY THERMAL GASIFICATION PROCESSES
}

\author{
Paulo Brito \\ Polytechnic Institute of Portalegre \\ Campus Politécnico, 10, 7300-555 Portalegre, Portugal \\ e-mail: pbrito@estgp.pt
}

\begin{abstract}
The sustainable energy will play a key role in the future of the planet, not only because in 20 years Biomass is expected to deliver around 30\% of total energy consumption, but also because BioEnergy, produced mainly through combustion and gasification of agro-industrial waste, woody materials and forest crops, is expected to be fundamental for sustainable energy production. Problems related to the emissions of greenhouse gases, lack of fossil natural resources and the increasing price of fuels have progressively encouraged research and adoption of new technological strategies for energy production from renewable sources and application of waste-to-energy (WTE) concepts. Syngas obtained from gasification of biomass and industrial wastes constitutes an interesting resource for energy generation because it has lower impacts for the environment compared to traditional technologies and allows for the valorisation of waste residues as feedstock. This work presents the scope, potential and technologies related to the use of biomass resources with a focus on thermal gasification of wastes.
\end{abstract}

Keywords: Biomass, wastes energetic valorisation, thermal gasification.

\section{INTRODUCTION}

The rise in the average temperature of the planet and an increasing production of residues by the society are two main problems that humanity has to resolve. The first problem results from the rise of carbon dioxide emissions during the last 200 years due to the massive use of fossil fuels, and therefore it is imperative to develop new sources and ways for energy and fuel production that can be sustainable and simultaneously with neutral emissions of carbon dioxide. The second problem is the consequence of the increasing production of residues and effluents resulting from the growing of human population and from the way that consumer goods are commercialized [1-2].

Biomass was one of the first sources of energy to be discovered and used by mankind and can one possible solution for the issues. There are basically three types of biomass materials, which are classified according to their origin. Energy crops, which are grown primarily for the production of energy. Another type of biomass consists of agricultural and forest residues that are generated when grains are harvested, trees pruned and cut down, such as, for example, straw, tips from the pruning of vineyards and olive groves, waste materials resulting from the pruning, cleaning and lopping of forests. These waste materials are particularly suited for use as sources of energy for the farms themselves, in order to increase the yield of growing chains. Finally, we have the by-products and organic waste that is generated in the processing of biomass for the development of food products, from which energy can be recovered. These by-products include organic waste from the agri-food sector, waste from farming and cattle-raising and waste from the industrial processing of wood and plant fibres; organic waste includes a portion of household waste and sludge from domestic and industrial effluents, such as, for example, food production waste [3-4]. 


\section{ART'TlE $Y^{2}$}

Ipplied Researthes in Technics, Technologies and Bduration

Journal of the Faculty of Technics and Technologies, Trakia University https://sites.google.com/a/trakia-uni.bg/artte/

Taking into account the availability of existing land around the globe and the fact that the supply of food to people in sufficient quantity is considered a priority, it can easily be seen that the amount of land available for biomass cultivation is limited and will become increasingly limited the greater the rate of growth in world population. Thus, alternative sources of biomass must be envisaged that do not involve the cultivation of raw materials that are also food crops or that are produced in rich soils which can be used for food production. Second generation biofuels, whose raw materials are non-food substances or agro-industrial and forestry waste, have been prioritised for development.

The various types of biomass and residues can be treated by chemical, biochemical or thermochemical processes with the aim of producing energy in various forms including electrical, mechanical or thermal energy. Essentially, these processes may be divided into two classes: thermochemical processes (e.g. combustion, gasification, pyrolysis, liquefaction and transesterification) or biochemical processes (e.g. anaerobic digestion and fermentation). Each one may be preceded by various pre-treatment operations with the aim of preparing the materials, ensuring that the process itself occurs in an efficient manner. Physical drying, sorting, compressing and cutting/breaking operations may be cited as some examples of these pre-treatments [5].

Combustion is the transformation of the chemical energy of fuel into heat through reactions with oxygen. For energy purposes, direct combustion occurs mainly in stoves, furnaces and boilers, with formation of steam that can be used for heating applications or for electricity production via a turbine coupled to a generator. This process is inefficient and generates appreciable amounts of gaseous contaminants with harmful effects for health and environment, forcing the implementation of expensive equipment for decontamination.

Pyrolysis is the process of converting a fuel (usually firewood) into another with a better energy density, such as charcoal. The process consists of heating the material in a nonoxidative atmosphere until the volatile material is removed. The main end product (charcoal) has an energy density twice that of the source material and burns at much higher temperatures. Apart from charcoal and fuel gas, pyrolysis produces coal tar and pyroligneous acid that, when sometimes submitted to further treatments like distillation, may create a new liquid fuel with good calorific properties. Pyrolysis may be an interesting pathway for the valorisation of lipid residues like used vegetable oils but not for those with high moisture contents like sewage sludges [6].

Gasification is a process of converting solid fuels into a syngas through thermochemical reactions involving lower stoichiometric quantities of oxygen when compared with combustion. This atmosphere poor in oxygen may be created by adding lower amounts of air or other gases such as steam and carbon dioxide, and which are named the oxidizing agent. There are several types of gasifiers and the most commonly used are fixed or fluidised bed reactors. The syngas is usually a mixture of carbon monoxide, hydrogen, methane, carbon dioxide and nitrogen in different proportions, which can be used to generate electricity, for example, in an internal combustion engine. The environmental impact of the flue gases after the combustion of syngas is generally lower than that which results from direct combustion of feedstock. Unlike pyrolysis, gasification may tolerate feedstocks with greater moisture contents.

A gasification plant is generally composed by four basic modules: a pre-treatment stage of feedstock, conversion of materials through gasification reactions, cooling and clean-up of product gas and a final stage for energy generation. Figure 1 summarizes the connection between these modules and also the main inputs and outputs of the process. 


\section{IRTITE}

Ipplied Researroches in Technics, Technologies and Bduration

Journal of the Faculty of Technics and Technologies, Trakia University https://sites.google.com/a/trakia-uni.bg/artte/

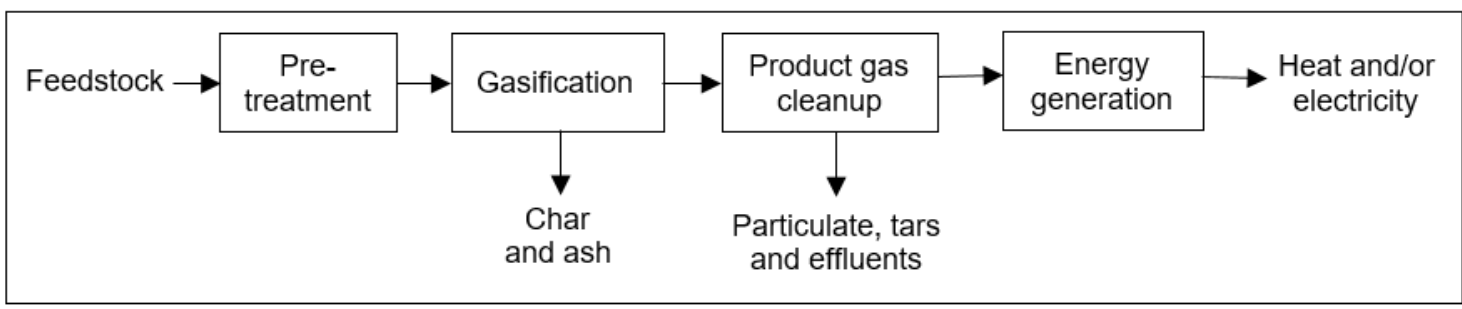

Figure 1. Process steps in a gasification plant (adapted from the text of [7]

This work presents the scope, potential and technologies related to the use of biomass resources with a focus on thermal gasification of industrial, agricultural and forest wastes.

\section{DEMONSTRATION UNITS}

Inside the facilities of IPP there are two thermal gasification units at pilot scale that allow the development of experiments using different types of biomass, with a view of demonstrating this technology for energy valorisation purposes. These pilot scale units are of downdraft and fluidized bed types with maximum processing capacities of around 22 and $100 \mathrm{~kg} / \mathrm{h}$. In the context of this work, some results obtained in both units will be presented.

Figure 2 displays a diagram of the gasification unit of fluidized bed type used in the experiments. The main components of the unit are:

- a biomass feeding system with two in-line storage tanks that allow the discharge of biomass into the reactor using an Archimedes screw at a variable and controllable speed; these two storage tanks act as buffers to avoid the entrance of air through the feeding system;

- a fluidized bed reactor with a tubular configuration, $0.5 \mathrm{~m}$ in diameter and $4 \mathrm{~m}$ of height; internally, this reactor is coated with ceramic refractory materials. Biomass enters the reactor at the height of $0.5 \mathrm{~m}$ from its base, and preheated air enters through the bottom side through a set of diffusers that ensure a flow of about $70 \mathrm{~m}^{3} / \mathrm{h}$. Three temperature sensors are installed uniformly along the height in order to monitor and control the gasification temperature, that typically is set around $800^{\circ} \mathrm{C}$. The syngas leaves the reactor from its top at about $700^{\circ} \mathrm{C}$. The reactor operates at negative pressure gradient produced by a vacuum pump installed at the end of the process line, and temperature control is achieved by tuning the air flow rate. During the experiments, the bed was filled with dolomite acting as an agent for tar reduction;

- a gas cooling system consisting of two heat exchangers: the former cools the syngas to about $300{ }^{\circ} \mathrm{C}$ using an air co-current flow that enters the reactor, while this flux is simultaneously pre-heated; the second heat exchanger cools the syngas down to $150^{\circ} \mathrm{C}$ by a forced flow of air coming from the exterior;

- a cellulosic bag filter that allows the removal of particulates and ashes produced during the gasification process. The cleaning of the filter is made by pressurized syngas injection in periodic intervals; particulates are collected at the bottom of the bag filter and are stored in a proper tank;

- a condenser, where liquid condensates are removed by cooling the syngas down to room temperature on a third tube heat exchanger;

- a control station, that allows the operation and monitoring of the several parameters along all the unit. 


\section{IRTTIE}

Ipplied Reserertches in Technics, Technologies and Bduration Journal of the Faculty of Technics and Technologies, Trakia University https://sites.google.com/a/trakia-uni.bg/artte/
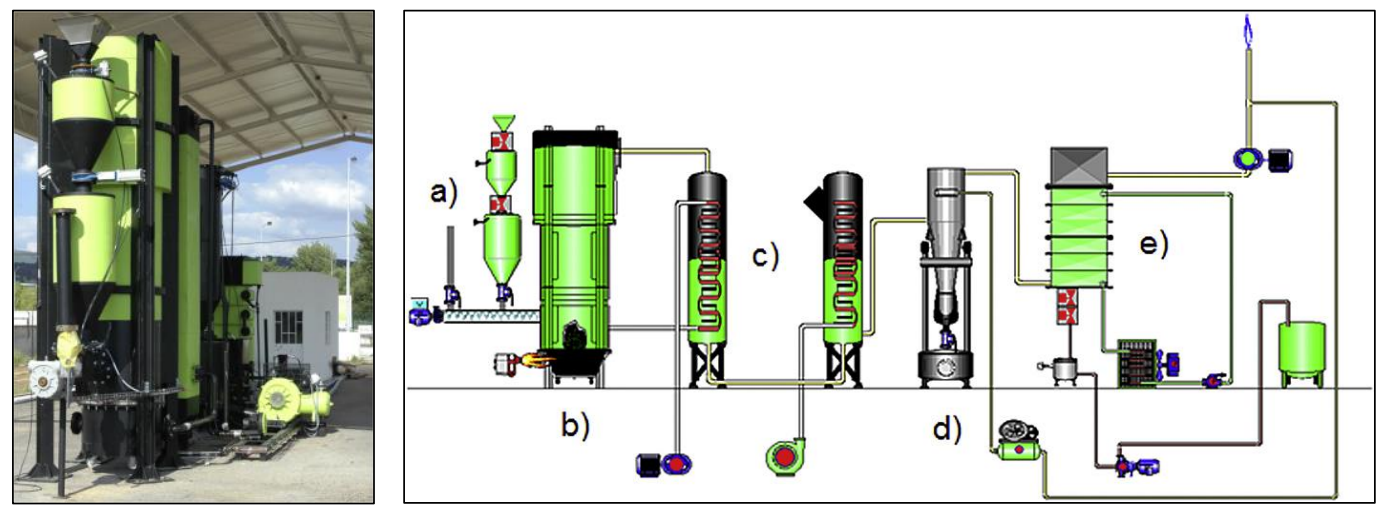

Figure 2.

Image of the fluidized bed gasification plant (left side) and schematic of operation (right side):

a) feeding system; b) reactor; c) heat exchangers; d) bag filter and e) condenser [8]

Tests with this unit were made using different biomasses at around $800{ }^{\circ} \mathrm{C}$, with mass admission rates of 40 and $63 \mathrm{~kg} / \mathrm{h}$ for studying syngas composition as a function of feedstock type and operational conditions.

The downdraft unit is a PP20 Power Pallets - 20kW gasifier from AllPowerLabs as shown in Figure 3, which is a combination of Imbert style downdraft fixed bed reactor, an electric power generator and an electronic control unit. The equipment is composed of a storage hopper of biomass, where it is simultaneously dried through the recirculation of the hot gases produced in the reactor. The biomass is supplied from the top while the air moves downwards, and which was previously heated through contact with the walls of the reactor. Ash collection is carried out in a separate tank in the lower zone of the reactor, while the syngas passes through a cyclone to remove fine particles. The syngas is conducted again to the biomass hopper in order to dry it, as already mentioned, and then is subjected to a new decontamination by a filter composed of biomasses of various granulometries. The syngas may be collected in this filter for analysis or directly injected into the generator. Condensates are also retained in this filter.
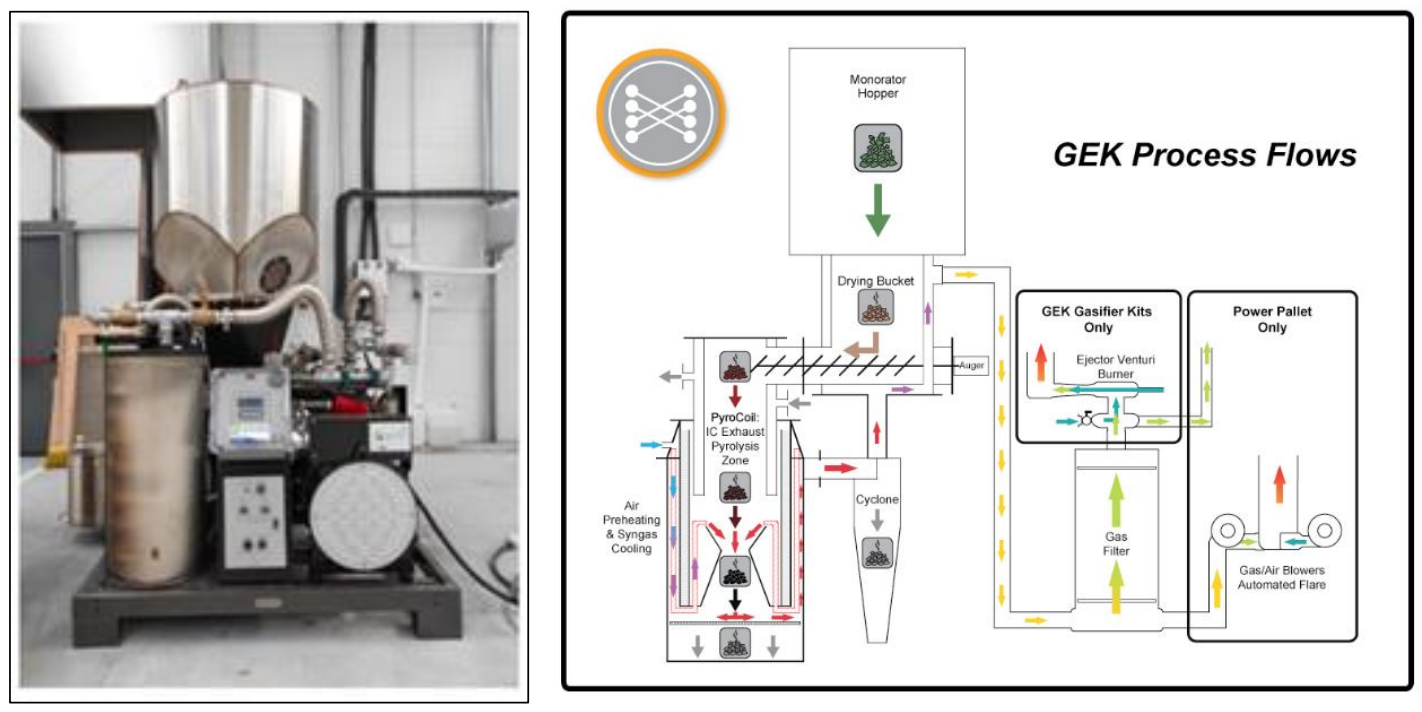

Figure 3. Image of the downdraft gasifier (left side) and schematic of operation (right side)

IRTIIE Vol. 6, No. 2, 2018 ISSN 1314-8788 (print), ISSN 1314-8796 (online), doi: 10.15547/artte.2018.02.012 


\subsection{Analysis of the composition and properties of the syngas}

Syngas analysis was performed in a Varian 450-GC gas chromatograph with two TCD detectors that allow the detection of $\mathrm{H}_{2}, \mathrm{CO}, \mathrm{CO}_{2}, \mathrm{CH}_{4}, \mathrm{O}_{2}, \mathrm{~N}_{2}, \mathrm{C}_{2} \mathrm{H}_{6}, \mathrm{C}_{2} \mathrm{H}_{4}$, and which also contains a CP81069, CP81071, CP81072, CP81073 and CP81025 Varian GC columns.

\section{GASIFICATION RESULTS}

\subsection{Gasification}

The compositions and lower heating value (LHV) of the different syngas produced, with the bubble fluidized bed reactor from different biomasses, are presented in Table 1. LHV's were calculated on basis of syngas composition determined by gas chromatography and using the standard combustion heats of the compounds obtained, at $25^{\circ} \mathrm{C}$.

Table 1. Experimental conditions and syngas analyses resulted from gasification of diverse biomasses

\begin{tabular}{|l|c|c|c|c|}
\hline Experimental conditions & $\begin{array}{c}\text { Forest } \\
\text { residues }\end{array}$ & Olive bagasse & Vines pruning & $\begin{array}{c}\text { Coffee } \\
\text { grounds }\end{array}$ \\
\hline Temperature $\left({ }^{\circ} \mathrm{C}\right)$ & 815 & 791 & 815 & 736 \\
\hline Equivalence Ratio, $\mathrm{O}_{2} / \mathrm{O}_{2}$ stoich. & 0,25 & 0,25 & 0,30 & 0,27 \\
\hline Admission Biomass $(\mathrm{Kg} / \mathrm{h})$ & 63 & 54 & 55 & 62 \\
\hline Air Flow Rate $\left(\mathrm{Nm}^{3} / \mathrm{h}\right)$ & 94,0 & 85,0 & 40,0 & 88,0 \\
\hline Syngas flow rate $\left(\mathrm{Nm}^{3} / \mathrm{h}\right)$ & 106,0 & 122,2 & 102,0 & 83,3 \\
\hline Condensates $(\mathrm{l} / \mathrm{h})$ & 4,6 & 3,9 & 4,1 & 11,0 \\
\hline Ash $(\mathrm{Kg} / \mathrm{h})$ & 0,3 & 0,3 & 0,2 & 1,0 \\
\hline Syngas fraction (dry basis) & & & & \\
\hline $\mathrm{CO}_{2}$ & 16,7 & 16,2 & 17,9 & 15,7 \\
\hline $\mathrm{N}_{2}$ & 48,0 & 52,2 & 49,1 & 53,5 \\
\hline $\mathrm{CH}$ & 4,6 & 4,42 & 2,3 & 1,2 \\
\hline $\mathrm{CO}$ & 18,6 & 18,1 & 14,1 & 12,6 \\
\hline $\mathrm{H}_{2}$ & 8,2 & 4,2 & 12,7 & 12,1 \\
\hline Syngas $\mathrm{LHV}\left(\mathrm{MJ} / \mathrm{Nm}^{3}\right)$ & 4,9 & 4,3 & 4,0 & 3,3 \\
\hline Syngas $\mathrm{LHV}(\mathrm{MJ} / \mathrm{kg} \mathrm{biomass})$ & 4,1 & 3,5 & 3,4 & 2,9 \\
\hline
\end{tabular}

Generally, the results show that the produced syngas is relatively rich in carbon monoxide (mass percentage between 11 to $19 \%$ ), methane (1 to $7 \%$ ) and hydrogen (4 to $13 \%$ ), and therefore these three gases are the main responsible for the heat content of the syngas produced. LHV's values are between 3.3 and $5.8 \mathrm{MJ} / \mathrm{Nm} 3$, as can be seen in table 3 . On the other hand, it can be seen that the syngas also contains a large amount of nitrogen (43 to 54 $\%$ ) and some carbon dioxide (16 to $19 \%$ ) resulting from the partial combustion process that takes place simultaneously with biomass gasification.

In a first approach, it may be said that the gas composition, the syngas fraction and the amount of ashes and condensates, are a function of biomass nature and its elemental composition, and of the gasification operational conditions, in particular, are a function of temperature process.

Generically, the results obtained with the various biomass studied shows a relation between the biomass calorific value and the calorific value of the syngas obtained: higher biomass

IRTIIE Vol. 6, No. 2, 2018 ISSN 1314-8788 (print), ISSN 1314-8796 (online), doi: 10.15547/artte.2018.02.012 


\section{ARTTIE $Y$}

Ipplied Researr'hes in Technics, Technologies and Bdurition

Journal of the Faculty of Technics and Technologies, Trakia University https://sites.google.com/a/trakia-uni.bg/artte/

calorific value results in higher calorific syngas production. In fact, it demonstrates that the syngas formed with the highest calorific value was obtained by gasification of forest residues, Miscanthus and Olive Bagasse, were the more energetic materials. This relationship between the biomass calorific content and the syngas LHV can be explained considering first, that, the biomass calorific value is related to the amount of carbon and hydrogen present in the biomass, i.e. an increased amount of carbon and hydrogen, lead to higher calorific value, and, second, a larger amount of these two elements allows production of larger quantities of hydrogen and carbon monoxide, the major contributors for the calorific value of the syngas.

Analysis of the dependence of producer gas properties in conditions of biomass admission shows, for all biomasses studied, there is a decrease in syngas calorific value with increasing quantity of biomass admitted. This is consistent with the fact of a faster acceptance of biomass by the reactor causes a reduction of the equilibrium reactions that are represented by equations 1 and 2 are not attained.

In general terms, an increase in gasification temperature promoted the formation of a syngas with higher hydrogen and carbon monoxide contents and, consequently, a higher LHV of the syngas. This could be a result of a shifting in the gasification equilibrium, since reaction represented by equation 2 is endoenergetic and, therefore favoured by a temperature increase. The increase of ER has a negative effect on $\mathrm{H} 2$ production because the oxidation reactions are favoured when the reactions had higher contents of oxygen. On the other hand, the increase of ER has a positive effect on the reduction of tar content with increased gas yield. The use of steam as a gasifying agent in gas-phase reactions could be a way to increase the decomposition of hydrocarbons and to rise contents of $\mathrm{H} 2$. The introduction of steam also leads to more tar participating in steam reforming, which led to a rapid increase of gas yield and tar reduction because of higher conversion efficiency [9].

\subsection{Co-gasification}

Table 2 presents the results of co-gasification of industrial waste, namely, tires and plastics with the pilot downdraft reactor. The advantage of the co-gasification processes is that they allow to reduce negative processing effects, often making feasible certain resources. The gasification of tires and plastics, in an isolated way, proved impossible to perform in this type of reactors studied, because of problems resulting from the decomposition process itself. Thus, in this case, the tests were carried out through co-gasification with acacia, a material that presents a good gasification easiness and produces relatively low content of ashes, presenting in addition great abundance in the region.

A first analysis of the results shows that the gas produced in greater quantity is the carbon monoxide followed by hydrogen, this situation having occurred in any of the mixtures tested. The third one is methane. The high percentage of nitrogen is due to the fact that gasification has been carried out with atmospheric air.

An interesting aspect of the presented results is that the addition of meat meal to the acacia leads to a significant increase in the calorific value of the gas, as a consequence of the significant increase of carbon monoxide and hydrogen. If such effect is positive at lower addition percentages in the co-gasification mixtures, when this percentage increases it is not at all possible to carry out the gasification process because of difficulties in the physical consistency of the material. An explanation for an increase in calorific power with small additions of meat meal may be due to the high concentration of oxygen in the pellets of meat meal (elemental analysis about $52 \%$ ) which, when reacting with acacia, does not require as much atmospheric oxygen (air inlet to the reactor) to perform the combustion and gasification reactions inside the reactor, so the presence of nitrogen is not as high and the concentration of $\mathrm{CO}$ increases substantially. Due to the difficulties of feeding with larger percentages of

IRTIIE Vol. 6, No. 2, 2018 ISSN 1314-8788 (print), ISSN 1314-8796 (online), doi: 10.15547/artte.2018.02.012 


\section{ARTTIE $Y$}

Ipplied Resseirl'hes in Teednicis, Technologies and Eductation

Journal of the Faculty of Technics and Technologies, Trakia University https://sites.google.com/a/trakia-uni.bg/artte/

meat meal, especially inside the reactor, where the pellets of meat meal completely clogged, an increase in calorific power was not observed. Other authors also reported the same phenomenon, where it is unreasonable to increase the percentage of meat meal due the problems of sealing inside the reactor and blocking of air intake [10-11].

Considering the high carbon content of used tires, this may lead to the creation of conditions for the production of high quantities of ash rich in chars, in the gasification process. Several studies point to the need for increase the co-gasification temperature, as the percentage of tires in the mixture increases, or to reduce the size of the tire particles to reduce the production of char [9]. The results show that the optimum conditions places precisely at low tire percentages (below 40\%). This may be one of the justifications presented so that, with the increase in mixing, the calorific value of the gas will decrease, and there will also be a lot of material that does not combust inside of the reactor at the end of the test [12].

In the case of the results with plastics, a rather abnormal behavior was observed in the increase of calorific value of the gas for the mixture of $40 \%$, when the temperature of the reactor is increased. This fact is reported by several authors [13], where it is also observed that an increase of gasification temperature for biomass with these characteristics, results in an increase of the calorific value of the gas [14].

Table 2. Experimental conditions and syngas analyses of co-gasification of acacia with different residues in the downdraft reactor.

\begin{tabular}{|c|c|c|c|c|c|}
\hline \multirow{2}{*}{ Experimental conditions } & \multirow{2}{*}{ Acacia } & \multicolumn{2}{|c|}{ Meat and bone } & \multicolumn{2}{|c|}{ Tires } \\
\hline & & $20 \%$ & $40 \%$ & $20 \%$ & $40 \%$ \\
\hline Temperature $\left({ }^{\circ} \mathrm{C}\right)$ & 805 & 823 & 761 & 803 & 790 \\
\hline Admission Biomass $(\mathrm{Kg} / \mathrm{h})$ & 3.5 & 2 & 1.3 & 4.974 & 1.755 \\
\hline Condensed (I/h) & 0.361 & 0.259 & 0.259 & 0.038 & 0.038 \\
\hline Ash $(\mathrm{Kg} / \mathrm{h})$ & 0.04 & 0.033 & 0.033 & 0.231 & 0.231 \\
\hline \multicolumn{6}{|l|}{ Syngas fraction (dry basis) } \\
\hline $\mathrm{CO}_{2}$ & 10.4 & 14.4 & 12 & 10 & 12.2 \\
\hline $\mathrm{N}_{2}$ & 53.9 & 44.3 & 55.9 & 54.3 & 56.1 \\
\hline $\mathrm{CH}_{4}$ & 3.6 & 3.3 & 3 & 3.6 & 2.3 \\
\hline $\mathrm{CO}$ & 5.8 & 15.9 & 5.6 & 10 & 10.7 \\
\hline $\mathrm{H}_{2}$ & 4.0 & 10.7 & 4 & 6.8 & 6.9 \\
\hline Syngas LHV $\left(\mathrm{MJ} / \mathrm{Nm}^{3}\right)$ & 3.34 & 4.56 & 2.3 & 3.64 & 3.14 \\
\hline
\end{tabular}

\section{CONCLUSIONS}

The present study aimed to test the use of the thermal gasification process as a way to valorise waste residues into a useful gas for energy production purposes, as well as to evaluate the economic feasibility of the construction of a plant able to process residues produced in a municipality.

The results demonstrated the feasibility of transforming forest residues and highly polluting waste into valuable, hydrogen-rich gas and other products that are highly relevant in terms of heating power and are of interest to the chemical industry.

In addition, a strategy for using biomass should involve investment in small production units near the biomass resource to be processed, allowing transport costs to be minimised. 


\section{ART'TE}

Ipplied Resseirl'hes in Teednicis, Technologies and Bductition Journal of the Faculty of Technics and Technologies, Trakia University https://sites.google.com/a/trakia-uni.bg/artte/

\section{REFERENCES}

[1] Z. Han, H. Ma, G. Shi, L. He, L. Wei, Q. Shi, A review of groundwater contamination near municipal solid waste landfill sites in China, Sci. Total Environ., vol. 569-570, pp. 1255-1264, 2016.

[2] P. Manara, A. Zabaniotou, Towards sewage sludge based biofuels via thermochemical conversion - A review, Renew. Sustain. Energy Rev., vol. 16, pp. 2566-2582, 2012.

[3] L. Lombardi, E. Carnevale, A. Corti, A review of technologies and performances of thermal treatment systems for energy recovery from waste, Waste Manag., vol. 37, pp. 26-44, 2015.

[4] M. C. Di Lonardo, M. Franzese, G. Costa, R. Gavasci, F. Lombardi, The application of SRF vs. RDF classification and specifications to the material flows of two mechanicalbiological treatment plants of Rome: Comparison and implications, Waste Manag., vol. 47, pp. 195-205, 2016.

[5] Basu, Prabir. Biomass gasification, pyrolysis and torrefaction - Practical design and theory. s.I.: Academic Press, 2013.

[6] Manara, P. and Zabaniotou, A. Towards sewage sludge based biofuels via thermochemical conversion - A review. s.l.: Renewable and Sustainable Energy Reviews, 2012. Vol. 16.

[7] A. Molino, S. Chianese, D. Musmarra, "Biomass gasification technology: The state of the art overview", J. Energy Chem., vol. 25, pp. 10-25, 2016.

[8] Couto, Nuno, et al. An experimental and numerical study on the Miscanthus gasification by using a pilot scale gasifier. s.I.: Renewable Energy, 2017.

[9] Straka, P., Kriz, V. and Z. Bucko, Co-Gasification of rubber with Brown coal, Acta Geodyn. Geomater, Vol. 5 (151), pp. 329-334. (2008).

[10] I. Gulyurtlu, D. Boavida, P. Abelha, MH. Lopes, I. Cabrita, Co-Gasification of coal and meat and bone meal, Fuel, 84 (17): 2137-2148. (2005).

[11] I. Gulyurtlu, D. Boavida, P. Abelha, P. Teixeira, T. Crujeira, F. Marques, I. Cabrita, Cocombustion for fossil fuel replacement and better environment, 7th European Conference on Industrial on Industrial Furnaces and Boilers, Porto, 18-21. (2006).

[12] Straka, P., Kriz, V. and Z. Bucko, Co-combustion of lignite/waste-tyre mixture in a moving bed, Fuel, 90: 1202-1206. (2009).

[13] G. Xiao, M. Ni, Y. Chi, K. Cen, Low-temperature gasification of waste tire in a fluidized bed, F. Energy Convers. Manag. 2008, 49, 2078-2082.

[14] U. Lee, J.N. Chung, H. Ingley, High-Temperature steam gasification of Municipal Solid Waste, Rubber, Plastic and Wood. Energy Fuels, 28, 4573-4587. (2014). 